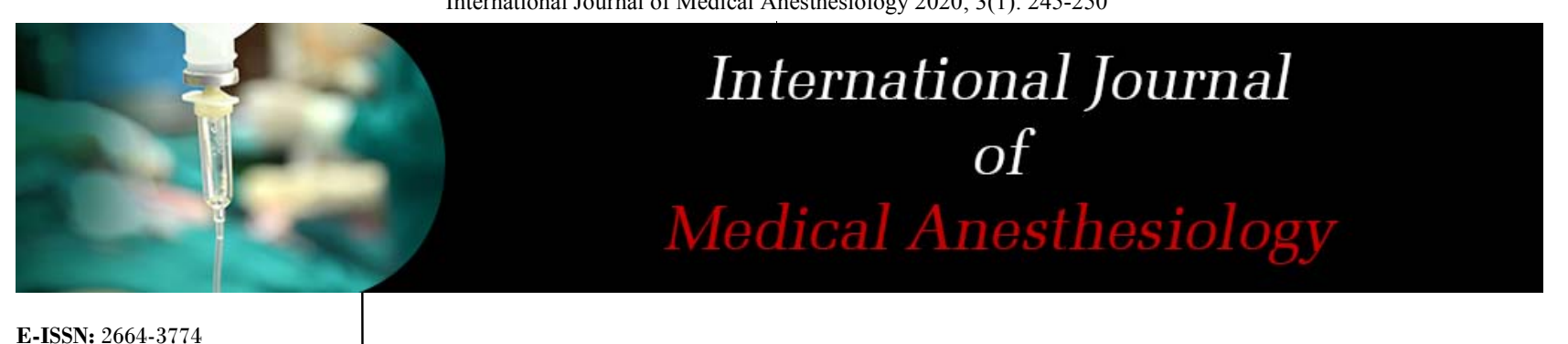

P-ISSN: 2664-3766

www.anesthesiologypaper.com

IJMA 2020; 3(1): 245-250

Received: 13-11-2019

Accepted: 15-12-2019

Ninad Deepak Chodankar

Department of

Anaesthesiology, Sir HN

Reliance Foundation Hospital,

Mumbai, Maharashtra, India

Bhagyashree Shivde

Department of

Anaesthesiology, Deenanath

Mangeshkar Hospital and

Research centre, Pune,

Maharashtra, India
Corresponding Author: Ninad Deepak Chodankar Department of

Anaesthesiology, Sir HN

Reliance Foundation Hospital,

Mumbai, Maharashtra, India

\section{A randomized controlled study of intravenous dexmedetomidine to attenuate the cardiovascular responses to laryngoscopy and endotracheal intubation}

\author{
Ninad Deepak Chodankar and Bhagyashree Shivde
}

DOI: $\underline{\text { https://doi.org/10.33545/26643766.2020.v3.i1d.96 }}$

\section{Abstract \\ Design: Prospective, Randomized, controlled study.}

Aims: Objective is to compare the efficacy of intravenous Dexmedetomidine in attenuating the cardiovascular response to laryngoscopy and endotracheal intubation.

Method: Study was done on 60 adults, ASA grade I or II normotensive patients, undergoing elective surgery under general anaesthesia and willing to participate. These patients were be randomly allocated in to either group C (Control), or D (Dexmedetomidine). Group ' $\mathrm{C}$ ' Control group. Group ' $\mathrm{D}$ ', patients were given intravenous Dexmedetomidine infusion $1 \mathrm{mcg} / \mathrm{kg}$ over 10 minutes, 3 minutes before start of laryngoscopy. All patients were premedicated, induced and intubated using Thiopentone and Succinyl Choline as per the protocol. Heart rate (HR), SBP, DBP and MAP were recorded at baseline (taken half an hour prior to anaesthesia), Before sedation, After induction but before intubation, Immediately after endotracheal intubation and Thereafter at 1,2,3, 4, 5 and 10 minutes.

Results: There was statistically significant rise in Heart rate after intubation in Group C compared to Group D, and difference was significant. After intubation, Heart rate continued to decrease and was significantly lower in Group D. There was statistically significant rise in MAP immediately after intubation in Group C compared to Group D.

Conclusion: We conclude that intravenous Dexmedetomidine $1 \mathrm{ug} / \mathrm{kg}$ is adequate to attenuate hemodynamic response to laryngoscopy and intubation.

Keywords: laryngoscopy, intubation, Dexmedetomidine, hemodynamic, response

\section{Introduction}

Laryngoscopy and endotracheal intubation is long standing basic requirement for general anaesthesia. It is often accompanied with significant increases in heart rate and arterial blood pressure, ${ }^{[1]}$ often leading to adverse outcome. These pressor responses are transient occurring 30 seconds after intubation and lasting less than 10 minutes ${ }^{[2]}$. This happens due to sympathetic system activation and can lead to cardiac rhythm abnormalities ${ }^{[3]}$.

These responses are most often of short duration and of little consequence in healthy individuals, serious complications can occur in patients with underlying coronary artery disease $^{[4]}$ reactive airways ${ }^{[5]}$.

These reflexes are mediated by the cardioaccelerator nerves and sympathetic system. This response includes wide-spread release of norepinephrine from adrenergic nerve terminals and secretion of epinephrine from the adrenal medulla ${ }^{[6]}$.

Dexmedetomidine is an imidazole derivative and highly selective central alpha2 adrenergic receptor agonist ${ }^{[7]}$. Alpha-2 agonists produce hyperpolarization of noradrenergic neurons and suppression of neuronal firing in the locus coeruleus leads to decreased systemic noradrenalin release results in attenuation of sympathoadrenal responses. Dexmedetomidine has been shown to provide hemodynamic stability during laryngoscopy and tracheal intubation ${ }^{[8]}$.

\section{Method}

Study period was from May 2015 to May 2016. 
Study Population: 60 adult ASA grade I or II normotensive patients, undergoing elective surgery under general anaesthesia and willing to participate were the study population.

Study Design: It is a prospective randomized study. The approval for the study was obtained from the Institutional Ethics Committee.

\section{Inclusion Criteria}

Male and female of age group between 25 to 65 years. Undergoing elective surgery under general anaesthesia. Weight $40 \mathrm{~kg}$ to $90 \mathrm{~kg}$. Resting systolic blood pressure less than $140 \mathrm{mmHg}$ and diastolic pressure less than $90 \mathrm{mmHg}$. American Society of Anaesthesiologist Grade I and II.

\section{Exclusion Criteria}

Ischemic heart diseases or ECG abnormalities indicating ischemic heart diseases. Patients with any overt cardiac, renal, pulmonary and liver diseases. Hypertensive patients. Any Patients with history of dyspnoea on exertion of grade III or more as per NYHA guidelines. Obesity (weight more than $90 \mathrm{~kg}$ ). Pregnancy. ASA grade III or IV patients. Anticipated difficult intubation. Any contraindication of Dexmedetomidine.

\section{Methodology \\ Pre-Operative Investigations and Assessment:}

A preoperative evaluation was carried out in all patients with demographic data like age, gender, weight and detailed clinical history, physical examination including, associated medical co-morbidities, and current medications. Blood pressure was measured at three occasions at least 1 hour apart to confirm that it fulfils the selection criteria. All routine and relevant investigations such as complete blood count, renal function test (serum electrolytes, serum creatinine, and blood urea levels), urine routine and microscopy, electrocardiogram, chest X-ray were carried out for all patients. The factors indicating difficult intubation on clinical examination were ruled out.

\section{Pre-Operative Management:}

All patients received Tablet Pantoprazole $40 \mathrm{mg}$ at night before surgery and 3 hours before surgery and Tablet Alprazolam $0.5 \mathrm{mg}$ was given night before surgery. A 20G intravenous cannula was secured on non-dominant hand in appropriate vein in wards and intravenous fluid Ringers Lactate $500 \mathrm{ml}$ as maintenance was started about 3 hours prior to surgery. About one hour prior to surgery, baseline readings were taken for pulse rate and blood pressures (Systolic, Diastolic and Mean) and were considered as preoperative baseline reading.

These patients were be randomly allocated in to either group C (Control) or D (Dexmedetomidine). Once group was decided, blinding was not maintained.

\section{In Operation Theatre}

In the preoperative area, monitoring of hemodynamic parameters such as Heart Rate, Non-invasive blood pressure monitoring (NIBP), oxygen saturation (SpO2) and Electrocardiography (ECG) was done. Five ECG leads were placed on chest and Lead II, Lead aVL and Lead V were continuously observed on monitor. In operation theatre monitoring of these parameters were continued. All the 3 groups received sedation with Intravenous Midazolam 0.02 $\mathrm{mg} / \mathrm{kg}$ and Fentanyl $2 \mathrm{mcg} / \mathrm{kg}$ about 15 minutes before induction. Preoxygenation with $100 \%$ oxygen by using facemask in closed circuit to achieve oxygen saturation (SpO2) of 98 - 99\% was done.

- For Group ' $\mathrm{C}$ ', patients were directly given inducing agent.

- For Group 'D', patients were given intravenous Dexmedetomidine infusion $1 \mathrm{mcg} / \mathrm{kg}$ over 10 minutes, 3 minutes before start of laryngoscopy.

Induction of anaesthesia was done with Intravenous Thiopentone $5 \mathrm{mg} / \mathrm{kg}$ body weight given slowly till loss of eyelash reflex is seen. Then intravenous Succinylcholine was given in dose of $2 \mathrm{mg} / \mathrm{kg}$. Then facemask ventilation was done till twitches disappears and adequate relaxation obtained. Direct laryngoscopy was conducted by the same anaesthesia consultant for all cases, using standard McIntosh blade and an appropriate size cuffed endotracheal tube lubricated with non-anaesthetic jelly and was inserted in single attempt and cuff will be immediately inflated with air to a pressure of $25 \mathrm{~cm}$ of water.

After confirming bilateral equality of air entry in lungs by auscultation, the endotracheal tube was secured with the adhesive tape. Ventilation was done by IPPV on ventilator. Ventilator setting was set to provide tidal volume of 8-10 $\mathrm{mg} / \mathrm{kg}$ and respiratory rate $14 /$ minute for 10 minutes. No noxious stimulus or surgical incision was applied over 10 minutes after intubation. Supine position was maintained. Anaesthesia was maintained using $50 \%$ nitrous oxide and $50 \%$ oxygen with Isoflurane (MAC-1.0). Hemodynamic parameters were monitored as follows: Heart rate (HR), Systolic blood pressure (SBP), Diastolic blood pressure (DBP), Mean Arterial Pressure (MAP) by non-invasive technique.

\section{The intervals for these measurements were:}

1. Baseline (taken half an hour prior to anaesthesia)

2. Before sedation

3. After induction but before intubation

4. Immediately after intubation

5. Thereafter at $1,2,3,4,5$ and 10 minutes.

After this monitoring for 10 minutes post-intubation, further operative and anaesthetic procedure were continued as per plan.

\section{Statistical methods}

- Statistical analysis was carried out with the help of SPSS (version 20) for Windows package (SPSS Science, Chicago, IL, USA). The description of the data was done in form of mean +/- SD for quantitative data while in the form of $\%$ proportion for qualitative (categorical) data. P-values of $<0.05$ will be considered significant.

- For quantitative data, Unpaired Student's t-test was used to test statistical significance of difference between two independent group means.

- For comparison of categorical variables chi-square test was used.

\section{Results}

Comparison of patient variables such as age, gender and weight shows that there is no statistically significant 
demographical difference between group C and D. (Table 1). Heart rate was lower in Group D as compared to Group C. There was no statistically significant difference at "baseline", "before sedation" or "after induction". Thereafter heart rate was statistically significant lower in Group D from "immediately after intubation" till "10 minutes after intubation”. (Table 2).

SBP was lower in Group D as compared to Group C. There was no statistically significant difference at "baseline", "before sedation" or "after induction". Thereafter SBP was statistically significant lower in Group D from "immediately after intubation" till "10 minutes after intubation". (Table $3)$.

DBP was lower in Group D as compared to Group C. There was no statistically significant difference at "baseline" or "before sedation". Thereafter DBP was statistically significant lower in Group D from "after induction” till "10 minutes after intubation". (Table 4).

MAP was lower in Group D as compared to Group C. There was no statistically significant difference at "baseline" or "before sedation". Thereafter DBP was statistically significant lower in Group D from "after induction" till "10 minutes after intubation”. (Table 5).

Table 1: Comparison of Patient variables

\begin{tabular}{|c|c|c|c|}
\hline \multirow{2}{*}{ Variables } & \multicolumn{2}{|c|}{ Group } & \multirow{2}{*}{ p-Value } \\
\cline { 2 - 3 } & Group C & Group D & \\
\hline Age & $36.03 \pm 9.219$ & $34.8 \pm 12.494$ & 0.666 \\
\hline Weight & $60.8 \pm 10.965$ & $65.4 \pm 9.103$ & 0.082 \\
\hline \multicolumn{4}{|c|}{ Gender } \\
\hline Male & 20 & 19 & \multirow{2}{*}{0.787} \\
\hline Female & 10 & 11 & \\
\hline
\end{tabular}

Table 2: Intergroup Comparison of mean Heart Rate between Group C and D

\begin{tabular}{|c|c|c|c|}
\hline & Group C & Group D & p-Value \\
\cline { 2 - 4 } & Mean \pm SD & Mean \pm SD & Group C vs D \\
\hline Baseline & $81.20 \pm 12.024$ & $80.60 \pm 11.267$ & 0.853 \\
\hline Before Sedation & $84.60 \pm 11.171$ & $80.57 \pm 11.392$ & 0.228 \\
\hline After Induction & $84.77 \pm 10.513$ & $79.67 \pm 11.081$ & 0.105 \\
\hline Immediately after Intubation & $101.60 \pm 11.935$ & $84.53 \pm 10.679$ & $0.000^{*}$ \\
\hline 1 min & $99.10 \pm 11.514$ & $82.53 \pm 9.365$ & $0.000^{*}$ \\
\hline 2 mins & $96.10 \pm 11.400$ & $80.87 \pm 9.566$ & $0.000^{*}$ \\
\hline 3 mins & $93.73 \pm 11.453$ & $79.71 \pm 9.158$ & $0.000^{*}$ \\
\hline 4 mins & $90.13 \pm 11.658$ & $78.13 \pm 9.213$ & $0.001^{*}$ \\
\hline 5 mins & $85.93 \pm 11.310$ & $76.97 \pm 9.427$ & $0.006^{*}$ \\
\hline * mins & $83.63 \pm 11.731$ & $75.23 \pm 9.957$ & $0.015^{*}$ \\
\hline *statistically significant & & &
\end{tabular}

Table 3: Intergroup Comparison of mean Systolic Blood Pressure between Group C and D

\begin{tabular}{|c|c|c|c|}
\hline & Group C & Group D & p-Value \\
\cline { 2 - 4 } & Mean \pm SD & Mean \pm SD & Group C vs D \\
\hline Baseline & $121.83 \pm 8.526$ & $121.33 \pm 9.260$ & 0.747 \\
\hline Before Sedation & $125.37 \pm 8.704$ & $121.40 \pm 9.437$ & 0.132 \\
\hline After Induction & $119.70 \pm 8.647$ & $121.50 \pm 9.332$ & 0.289 \\
\hline Immediately after Intubation & $161.90 \pm 11.929$ & $124.50 \pm 9.569$ & $0.000^{*}$ \\
\hline 1 min & $151.10 \pm 10.114$ & $121.43 \pm 8.912$ & $0.000^{*}$ \\
\hline 2 mins & $142.93 \pm 7.428$ & $118.33 \pm 8.636$ & $0.000^{*}$ \\
\hline 3 mins & $137.67 \pm 7.950$ & $117.10 \pm 8.385$ & $0.000^{*}$ \\
\hline 4 mins & $132.83 \pm 7.410$ & $114.87 \pm 8.386$ & $0.000^{*}$ \\
\hline 5 mins & $127.90 \pm 8.168$ & $112.67 \pm 8.547$ & $0.000^{*}$ \\
\hline 10 mins & $124.37 \pm 9.046$ & $111.30 \pm 8.567$ & $0.000^{*}$ \\
\hline
\end{tabular}

*statistically significant

Table 4: Intergroup Comparison of mean Diastolic Blood Pressure between Group C and D

\begin{tabular}{|c|c|c|c|}
\hline & Group C & Group D & p-Value \\
\cline { 2 - 4 } & Mean \pm SD & Mean \pm SD & Group C vs D \\
\hline Baseline & $78.50 \pm 6.073$ & $77.73 \pm 8.832$ & 0.678 \\
\hline Before Sedation & $77.40 \pm 6.306$ & $78.60 \pm 7.445$ & 0.485 \\
\hline After Induction & $74.47 \pm 6.241$ & $78.03 \pm 7.337$ & $\mathbf{0 . 0 3}^{*}$ \\
\hline Immediately after Intubation & $94.13 \pm 7.366$ & $79.80 \pm 7.513$ & $\mathbf{0 . 0 0 0}^{*}$ \\
\hline 1 min & $88.57 \pm 7.463$ & $79.03 \pm 7.712$ & $\mathbf{0 . 0 0}^{*}$ \\
\hline 2 mins & $86.57 \pm 6.590$ & $77.37 \pm 7.513$ & $\mathbf{0 . 0 0 0}^{*}$ \\
\hline 3 mins & $83.87 \pm 6.202$ & $75.47 \pm 7.628$ & $\mathbf{0 . 0 0 0}^{*}$ \\
\hline 4 mins & $82.40 \pm 6.344$ & $73.60 \pm 7.686$ & $\mathbf{0 . 0 0 0}^{*}$ \\
\hline 5 mins & $79.33 \pm 4.908$ & $72.00 \pm 8.077$ & $\mathbf{0 . 0 0 0}^{*}$ \\
\hline 10 mins & $77.27 \pm 5.382$ & $69.73 \pm 8.292$ & $\mathbf{0 . 0 0}^{*}$ \\
\hline
\end{tabular}

*statistically significant 
Table 5: Intergroup Comparison of mean MAP between Group C and D

\begin{tabular}{|c|c|c|c|}
\hline & Group C & Group D & p-Value \\
\cline { 2 - 4 } & Mean \pm SD & Mean \pm SD & Group C vs D \\
\hline Baseline & $90.90 \pm 8.057$ & $92.50 \pm 12.857$ & 0.500 \\
\hline Before Sedation & $91.63 \pm 7.695$ & $93.87 \pm 12.005$ & 0.339 \\
\hline After Induction & $86.27 \pm 7.755$ & $96.17 \pm 11.308$ & $0.000^{*}$ \\
\hline Immediately after Intubation & $115.73 \pm 11.922$ & $97.37 \pm 10.227$ & $0.000^{*}$ \\
\hline 1 min & $112.73 \pm 10.945$ & $95.83 \pm 9.706$ & $0.000^{*}$ \\
\hline 2 mins & $108.47 \pm 9.899$ & $93.00 \pm 9.798$ & $0.000^{*}$ \\
\hline 3 mins & $103.57 \pm 9.555$ & $90.67 \pm 9.185$ & $0.000^{*}$ \\
\hline 4 mins & $99.93 \pm 8.706$ & $89.00 \pm 9.620$ & $0.000^{*}$ \\
\hline 5 mins & $95.00 \pm 7.344$ & $87.03 \pm 9.301$ & $0.000^{*}$ \\
\hline 10 mins & $90.93 \pm 7.148$ & $85.63 \pm 9.338$ & $0.005^{*}$ \\
\hline
\end{tabular}

*statistically significant

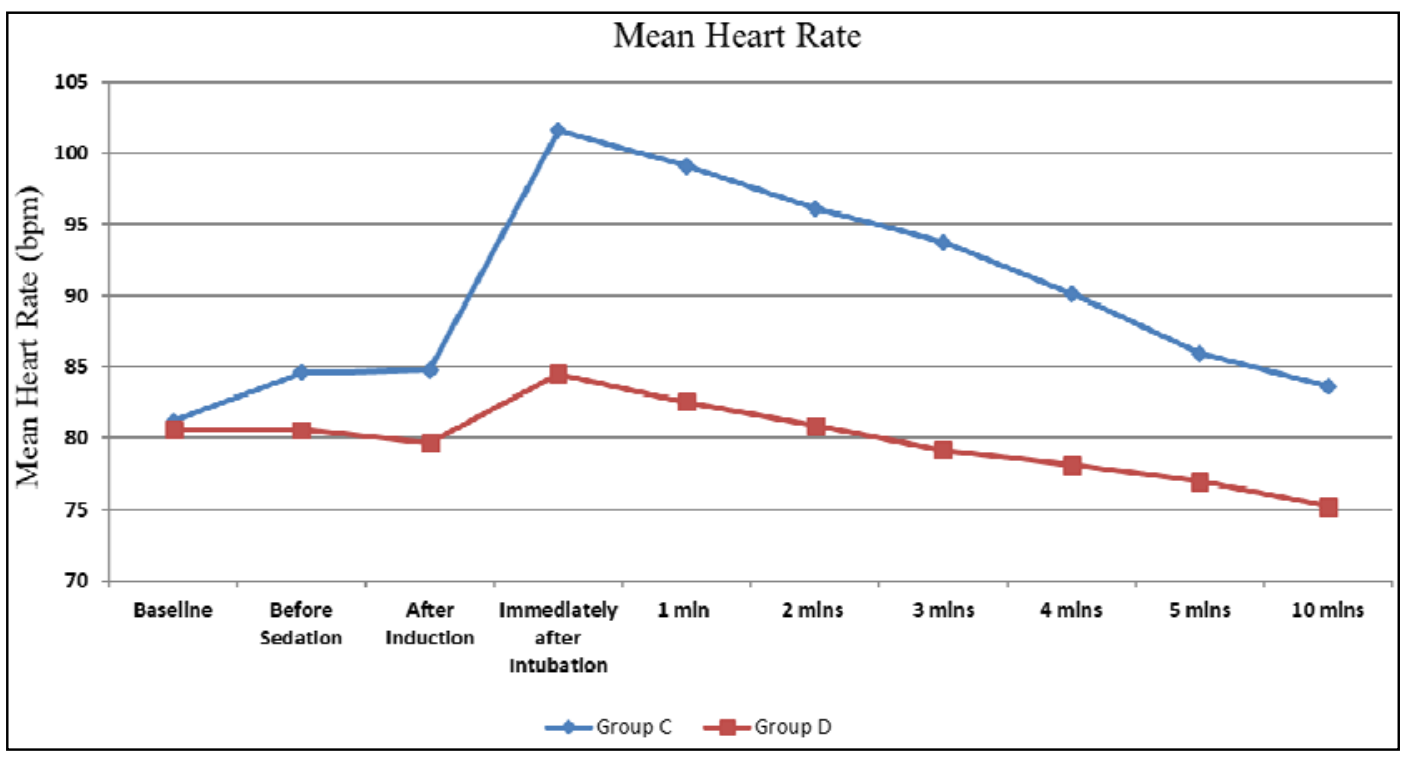

Graph 1: Comparison of Mean HR in Group C, D and E

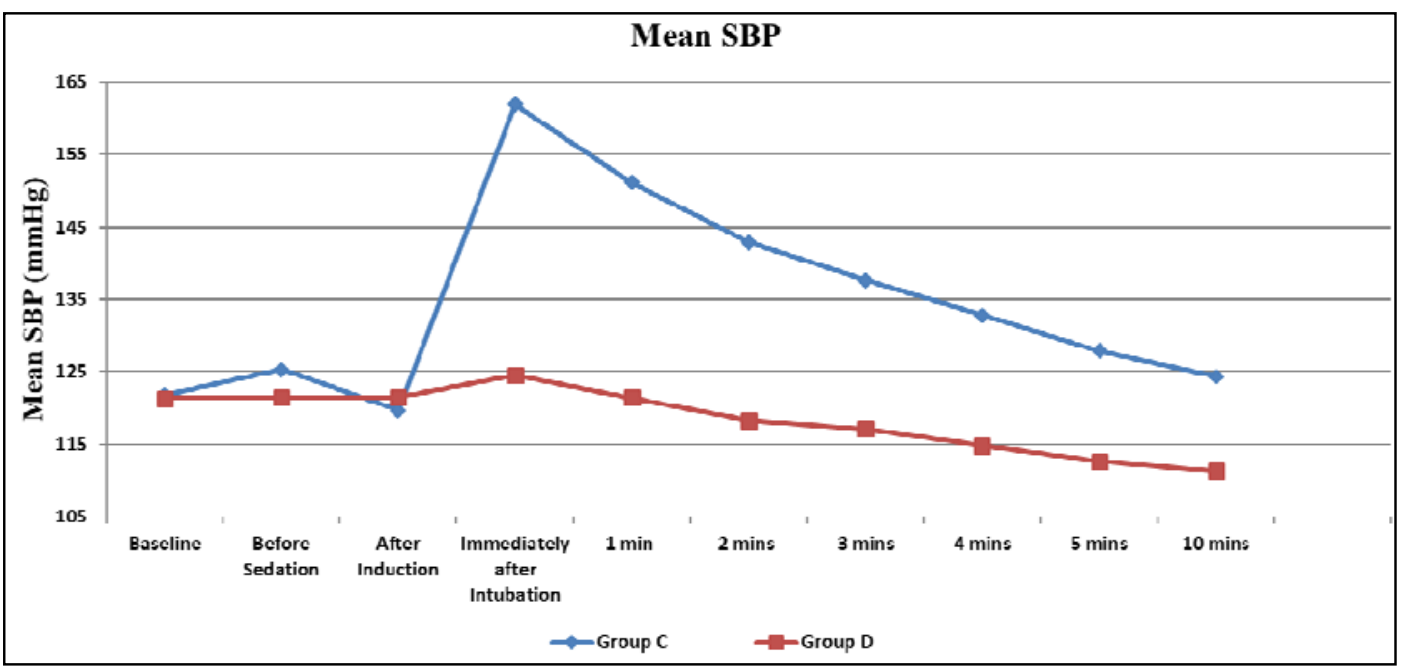

Graph 2: Comparison of Mean SBP in Group C, D and E 


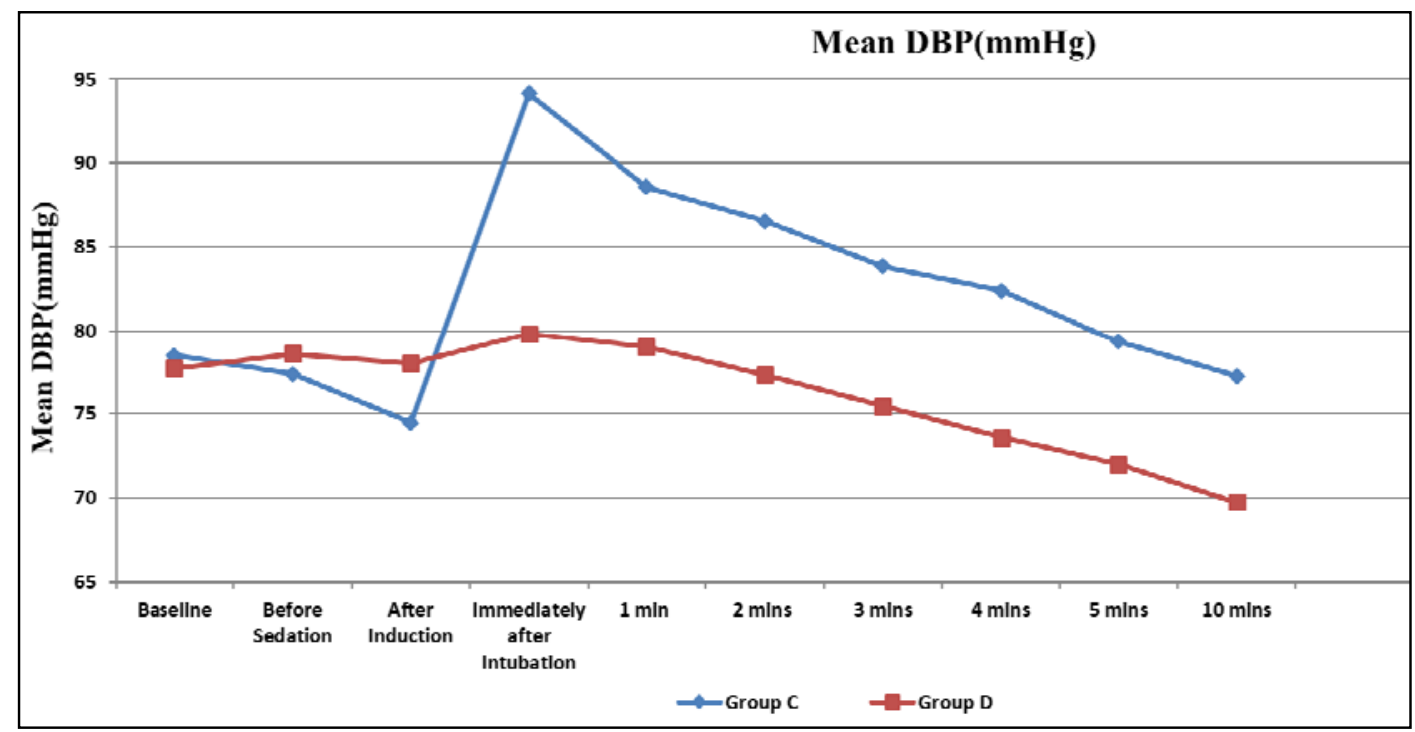

Graph 3: Comparison of Mean DBP in Group C, D and E

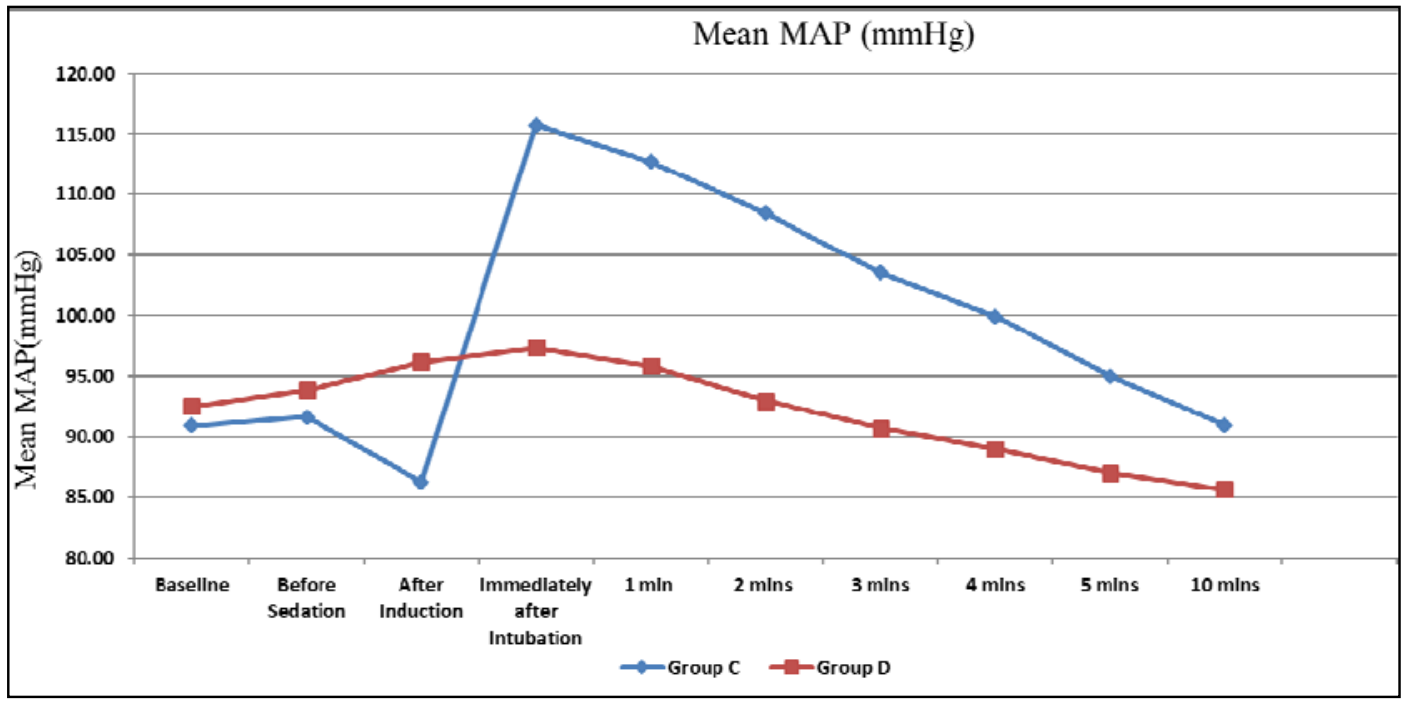

Graph 4: Comparison of Mean MAP in Group C, D and E

\section{Discussion}

The cardiovascular response which leads to hemodynamic pressor changes characterized by tachycardia and hypertension to manipulation in the area of the larynx, by means of laryngoscopy and intubation, is well-recognized. Stimulation of mechanoreceptors in the pharyngeal wall, epiglottis and vocal cords, is thought to be the cause for this hemodynamic response. Cardiovascular pressor response following laryngoscopy and tracheal intubation has been investigated extensively since the early days of anaesthesia [9].

Myocardial ischemia might occur during the inductionintubation sequence in patients with coronary artery disease. Intraoperative ischemia has been associated with a high rate of perioperative myocardial infarction ${ }^{[10]}$. During procedure like direct laryngoscopy involving severe sympathetic stimuli prevention of tachycardia, hypertension and rise in total oxygen consumption may prove beneficial in patients with limited cardiac reserve ${ }^{[11]}$.

Dexmedetomidine is a highly selective and specific alphatwo adrenergic agonist which produces its action by decreasing the catecholamine release from locus coeruleus in the brain. It decreases the cerebral blood flow (CBF) while preserving the $\mathrm{CBF}$-cerebral metabolic rate coupling, decreases intracranial pressure ${ }^{[12,13]}$. It also decreases sympathetic tone and their preoperative use has been shown to blunt the hemodynamic responses to laryngoscopy and intubation ${ }^{[14]}$.

Sagiroglu et al. ${ }^{[15]}$ concluded that the overall control of hemodynamic responses to tracheal intubation were better with Dexmedetomidine $1 \mu \mathrm{g} / \mathrm{kg}$ as compared to Dexmedetomidine $0.5 \mu \mathrm{g} / \mathrm{kg}$. Laha et al. ${ }^{[16]}$ in their study compared Dexmedetomidine $1 \mu \mathrm{g} / \mathrm{kg}$ with control and concluded that Dexmedetomidine effectively blunted the hemodynamic responses during laryngoscopy, and reduced anaesthetic requirements.

Kunisawa et al. ${ }^{[17]}$ reported that an injection of Dexmedetomidine inhibits a decrease in blood pressure caused by the anaesthetic agent, and so postulated that it may be the result of vasoconstriction caused by the alpha- 2 receptor in the vascular smooth muscle. The report stated that blood pressure temporarily increases one minute after an injection with a loading dose of Dexmedetomidine, and 
reaches its peak at $3 \mathrm{~min}$. When Dexmedetomidine is used in a combination with anaesthetics, it reportedly prevents further drops in blood pressure and rather inhibits it ${ }^{[18]}$.

Sulaiman et al. [19] studied efficacy of intravenous Dexmedetomidine for attenuation of cardiovascular responses to laryngoscopy and endotracheal intubation in patients with coronary artery disease. They observed that Dexmedetomidine at a dose of $0.5 \mathrm{mcg} / \mathrm{kg}$ as $10-\mathrm{min}$ infusion administered prior to induction of general anaesthesia was effective to attenuate the sympathetic response to laryngoscopy and intubation in patients undergoing myocardial revascularization.

In another study comparing Lignocaine and Dexmedetomidine ${ }^{[20]}$ they observed that hemodynamic stress response was seen following laryngoscopy and tracheal intubation was significantly attenuated in dexmedetomidine group.

Our study demonstrated that the use of Dexmedetomidine was effective in decreasing the hypertensive response to laryngoscopy and intubation.

\section{Conclusion}

In Normotensive patients requiring general anaesthesia with intubation, after induction with Fentanyl and Thiopentone, and Succinylcholine as muscle relaxant, we found that intravenous Dexmedetomidine $1 \mathrm{ug} / \mathrm{kg}$ is effective to attenuate hemodynamic response to laryngoscopy and intubation.

\section{Acknowledgements}

I express my sincere thanks to all my patients who made my research possible and meaningful.

\section{References}

1. Koji T, Kengo N, Massaki H. Cardiovascular response to rapid anaesthesia induction and endotracheal intubation. Anaesthesia and Analgesia. 1964; 43:201208.

2. Stoelting RK, Peterson C. Circulatory changes during laryngoscopy and tracheal intubation influence of duration of laryngoscopy with or without prior lidocaine. Anaesthesiology. 1977; 47:381-383.

3. Burstein CL, LoPinto FJ, Newman W. Electrocardiographic studies during endotracheal intubation. I. Effects during usual routine technics. Anaesthesiology. 1950; 11(2):224-37

4. Loeb HS, Saudye A, Croke RP. Effects of pharmacologically induced hypertension on myocardial ischemia and coronary hemodynamics in patients with fixed coronary obstruction. Circulation. 1978; 57:41-46

5. Dohi S, Gold M. Pulmonary mechanics during general Anesthesia. Br J Anaesth. 1979; 51:205-213) or intracranial neuropathology (Shapiro HM, Wyte SR, Harris AB. Acute intraoperative intracranial hypertension in neurosurgical patients: Mechanical and pharmacologic factors. Anesthesiology. 1972; 37:399405

6. Hassan HG, el-Sharkawy TY, Renck H. Hemodynamic and catecholamine responses to laryngoscopy with vs. without endo-tracheal intubation. Acta Anaesthesiol Scand. 1991; 35:442-447

7. Khan ZP, Ferguson CN, Jones RM. Alpha-2 and imidazoline receptor agonists- Their pharmacology and therapeutic role. Anaesthesia. 1999; 54:146-65.
8. Grewal A. Dexmedetomidine: New avenues. J Anaesthesiol Clin Pharmacol. 2011; 27:297-302

9. King BD, Harris LC Jr, Greifenstein FE, Elder JD Jr, Dripps RD. Reflex circulatory responses to direct laryngoscopy and tracheal intubation performed during general anesthesia. Anaesthesiology 1951; 12:556-66.

10. Chraemmer-Jørgensen B, Høilund-Carlsen PF, Marving J, Christensen V. Lack of effect of intravenous lidocaine on hemodynamic responses to rapid sequence induction of general anesthesia: A double-blind controlled clinical trial. Anesth Analg. 1986; 65:103741.

11. Mikawa K, Nishina K, Maekawa N, Obara $H$. Comparison of Nicardipine, Diltiazem and Verapamil for controlling the cardiovascular responses to tracheal intubation. British Journal of Anaesthesia. 1996; 76:221-226.

12. Drummond JC, Dao AV, Roth DM, Cheng CR, Atwater BI, Minokadeh A, et al. Effect of dexmedetomidine on cerebral blood flow velocity, cerebral metabolic rate, and carbon dioxide response in normal humans. Anesthesiology. 2008; 108:225-32.

13. Jolkkonen J, Puurunen K, Koistinaho J, Kauppinen R, Haapalinna A, Nieminen L, et al. Neuroprotection by the alpha2-adrenoceptor agonist, dexmedetomidine, in rat focal cerebral ischemia. Eur J Pharmacol. 1999; 372:31-6.

14. Aantaa R, Jalonen J. Perioperative use of alpha2adrenoceptor agonists and the cardiac patient. Eur J Anaesthesiol. 2006; 23:361-72.

15. Sagiroglu AE, Celik M, Orhon Z, Yüzer S, Sen B. Different doses of Dexmedetomidine on controlling hemodynamic responses to tracheal intubation. The Internet Journal of Anesthesiology, 2010; 27(2).

16. Laha A, Ghosh S, Sarkar S. Attenuation of sympathoadrenal responses and anesthetic requirement by dexmedetomidine. Anesth Essays Res. 2013; 7:6570 .

17. Kunisawa $T$, Nagata $O$, Nagashima M, Mitamura $S$, Ueno M, Suzuki A, et al. Dexmedetomidine suppresses the decrease in blood pressure during anesthetic induction an blunts the cardiovascular response to tracheal intubation. J Clin Anesth. 2009; 21:194-199.

18. Bloor BC, Ward DS, Belleville JP, Maze M. Effects of intravenous dexmedetomidine in humans. II. Hemodynamic changes. Anesthesiology. 1992; 77:1134-42.

19. Sulaiman S, Karthekeyan R, Vakamudi M, Sundar AS, Ravullapalli H, Gandham R, et al. The effects of dexmedetomidine on attenuation of stress response to endotracheal intubation in patients undergoing elective off-pump coronary artery bypass grafting. Annals of Cardiac Anaesthesia. Jan-Mar. 2012; 15(1):39-43.

20. Sale HK, Shendage VJ. Lignocaine and Dexmedetomidine in Attenuation of Pressor Response to Laryngoscopy and Intubation: A Prospective Study. International Journal of Scientific Study. December. 2015; 3(9):155-160 